\title{
Clinical and hematobiochemical response in canine monocytic ehrlichiosis seropositive dogs of Punjab
}

\author{
Manasa R. Kottadamane ${ }^{1}$, Pritpal Singh Dhaliwal ${ }^{1}$, Lachhman Das Singla², Baljinder Kumar Bansal ${ }^{1}$ \\ and Sanjeev Kumar Uppal ${ }^{1}$
}

\begin{abstract}
1. Department of Veterinary Medicine, College of Veterinary Sciences, Guru Angad Dev Veterinary and Animal Sciences University, Ludhiana, Punjab, India; 2. Department of Veterinary Parasitology, College of Veterinary Sciences, Guru Angad Dev Veterinary and Animal Sciences University, Ludhiana, Punjab, India.

Corresponding author: Manasa R. Kottadamane, e-mail: vetmanasa@gmail.com, Co-authors: PSD: dhaliwalpps@yahoo.com, LDS: Idsingla@gmail.com, BKB: baljinderbansal@rediffmail.com, SKU: skuppal@yahoo.com

Received: 22-07-2016, Accepted: 05-01-2017, Published online: 27-02-2017
\end{abstract}

doi: 10.14202/vetworld.2017.255-261 How to cite this article: Kottadamane MR, Dhaliwal PS, Singla LD, Bansal BK, Uppal SK (2017) Clinical and hematobiochemical response in canine monocytic ehrlichiosis seropositive dogs of Punjab, Veterinary World, 10(2): 255-261.

\begin{abstract}
Aim: As in India especially, the Punjab state sero-prevalence and distribution of ehrlichiosis in relation to clinicohematobiochemical response remains largely unexplored. Thus, this study was designed to determine the prevalence of vector (tick)-borne tropical canine pancytopenia caused by Ehrlichia canis through enzyme labeled ImmunoComb ${ }^{\circledR}$ (IC) assay in dogs from in and around Ludhiana, Punjab. Correlation of prevalence was made with various clinico-hematobiochemical parameters.
\end{abstract}

Materials and Methods: Seroprevalence study was carried out using IC ${ }^{\circledR}$ test kit (Biogal, Galed Labs). The study was conducted in 84 dogs presented to the Small Animal Clinics, Teaching Veterinary Clinical Complex, Guru Angad Dev Veterinary and Animal Sciences University, Ludhiana, Punjab.

Results: Out of 84 suspected dogs for ehrlichiosis, based on peripheral thin blood smear examination 12 (14.28\%) cases were positive for the morulae of E. canis and $73(86.90 \%)$ dogs were found positive to E. canis antibodies through IC ${ }^{\circledR}$ canine Ehrlichia antibody test kit, respectively. Among the different age groups 1-3 years of aged group showed highest prevalence $(41.09 \%)$, followed by the 3-6 years age group (32.87\%), infection levels were lower in the $<1$ year of age group dogs $(13.69 \%)$ and more than 6 years age group dogs $(12.32 \%)$. The highest prevalence was seen in Labrador retriever. This study indicates that season plays a very important role in the prevalence of ehrlichiosis. The most common findings observed were anemia, leukocytosis, neutropenia, lymphopenia, thrombocytopenia, eosinophilia followed by hyperbilirubinemia, increased levels of aspartate aminotransferase, alanine aminotransferase and alkaline phosphatase, hypoalbuminemia, hyperglobulinaemia, decrease in albumin and globulin ratio, increase in blood urea nitrogen and creatinine.

Conclusions: Serological techniques like $\mathrm{IC}^{\circledR}$ are more useful for detecting chronic and subclinical infections and are ideally suited to epidemiological investigations.

Keywords: dogs, Ehrlichia canis, ImmunoComb test, morulae.

\section{Introduction}

Canine ehrlichiosis a tick-borne disease (Rhipicephalus sanguineus, the brown dog tick) is caused by Ehrlichia canis obligatory intracellular small, Gram-negative, pleiomorphic obligate intracellular cocci that infect blood cells in canines which come under vector-borne diseases affecting dogs [1]. Clinical signs vary based on acute, subclinical and chronic phase. However, the disease is mainly characterized by high fever $\left(104-105^{\circ} \mathrm{F}\right)$, anorexia, weakness, epistaxis, lymphadenopathy, and edema of dependent parts [2].

Diagnosis is mainly based on routine blood smear examination. However, more sensitive and

Copyright: Kottadamane, et al. Open Access. This article is distributed under the terms of the Creative Commons Attribution 4.0 International License (http://creativecommons.org/licenses/ by/4.0/), which permits unrestricted use, distribution, and reproduction in any medium, provided you give appropriate credit to the original author(s) and the source, provide a link to the Creative Commons license, and indicate if changes were made. The Creative Commons Public Domain Dedication waiver (http:// creativecommons.org/publicdomain/zero/1.0/) applies to the data made available in this article, unless otherwise stated. specific molecular and serological diagnostics techniques can be used for confirmation of cases negative by microscopy. The gold standard test for detection of canine monocytic ehrlichiosis (CME) is indirect immunofluorescence antibody (IFA) test. However, this test has to be performed in selected laboratories and requires extensive equipment and trained personnel. Whereas, the enzyme-linked immunosorbent assay (ELISA) is a semiquantitive test where small quantities of antigen were used to detect the specific antibodies. Especially the commercially available dot-ELISA kits are used to detect the E. canis immunoglobulin- $\mathrm{G}$ ( $\mathrm{IgG}$ ) antibodies [3]. Among them being the ImmunoComb (IC) ${ }^{\circledR}$ (Biogal, Israel) dotELISA has been efficient in detecting anti-E. canis antibodies in sera from naturally infected dogs presenting symptoms [4].

Since not much work have been done on seroprevalence study in relation to hematobiochemical changes on ehrlichiosis in Punjab, India. Therefore, this study was conducted to investigate the serology 
based prevalence of $E$. canis infection and its correlation with the hematobiochemical findings.

\section{Materials and Methods}

Ethical approval

Permission for animal experiments has been taken by Committee for the Purpose of Control and Supervision of Experiments on Animals (CPCSEA) under the Ministry of Environment and Forests, Government of India. Further, for sample collection and to conduct other procedures, application was submitted to Instituitional Animal Ethics Committee (IAEC) for a period of 12 months and got approved to carry out the research work (Regn. No.497/GO/ $\mathrm{ab} / 2001$ ).

\section{Study area}

This study was conducted at Small Animal Clinics, Teaching Veterinary Clinical Complex, Guru Angad Dev Veterinary and Animal Sciences University, Ludhiana, Punjab, India. After complete clinical examination, $84 \mathrm{dogs}$ with the signs of ehrlichiosis and reduced platelet count were screened by both blood smear examination, and $\mathrm{IC}^{\circledR}$ dot-ELISA kit and samples were subjected to hematobiochemical studies.

\section{Hematobiochemical parameters}

The collected blood samples were subjected for complete hematology (hemoglobin $[\mathrm{Hb}]$, total leukocyte count [TLC], differential leukocyte count, and total platelet count) by ADVIA $^{\circledR} 2120$ (Hematology System, Siemens Healthcare Diagnostics Inc., USA), and serum samples were used for biochemical analysis (total bilirubin, aspartate aminotransferase [AST], alanine aminotransferase [ALT], alkaline phosphatase [ALKP], total protein, albumin, blood urea nitrogen [BUN], and creatinine) by automatic biochemical analyser (Johnson \& Johnson Diagnostic Kits, Mumbai, India). Results obtained from blood smear examination, hematobiochemical studies, and serological studies were compared and analyzed to get definitive diagnosis.

Serological detection of IgG anti-E canis antibodies by $\mathrm{IC}^{\circledR}$ canine Ehrlichia antibody test kit (Biogal, Galed Labs)

Serum samples obtained from the $0^{\text {th }}$ day blood samples of ehrlichiosis suspected dogs used for this study. As $0^{\text {th }}$ day animals were naturally infected by vector transmission presented to the clinic with the signs of ehrlichiosis. Serum samples from these animals were subjected to $\mathrm{IC}^{\circledR}$ canine Ehrlichia antibody test (Biogal Galed Lab., Israel) on the same day at room temperature $\left(20-25^{\circ} \mathrm{C}\right)$ and tests performed based on the manufacturer's instructions. The sensitivity of the test is $100 \%$ and specificity is $94.1 \%$. The test does not cross-react with other blood parasite antibodies. An equivalent intensity of the color reaction in comparison with a positive reference point was used as guide to denote the level of antibodies in each sample: Intense color reactions as compared to the reference spot were considered positive for antibodies against $E$. canis. Whereas a colorless or faint gray color reaction indicates either a negative result or undetectable levels of antibodies.

Antibody titers for the different "S" levels ( $\mathrm{IC}^{\circledR}$ scores) were followed as per manufactures protocol. The titers are graded as S1 and S2 (1:20-1:40), S3 and S4 (1:80-1:160), S5 and S6 (1:320-1:1280) [5]. Further to see the treatment efficacy, collected blood samples after $15^{\text {th }}$ and $21^{\text {st }}$ day of post treatment and subjected to nested polymerase chain reaction and to know the hematobiochemical improvement after $2^{\text {nd }}$ and $3^{\text {rd }}$ week of post-treatment.

\section{Statistical analysis}

The prevalence of the disease was determined with regard to months, season, age, breed and sex in the affected animals and possible hematobiochemical alterations and possible associations between the evaluated variables and positive reaction to the agents were determined. Further, to see any statistically significant differences among various hematobiochemical parameters between the positive groups and the control group were analyzed by one-way analysis of variance at 5\% level of significance using SPSS software (Tukey multiple comparison test).

\section{Results}

\section{Parasitological prevalence}

Examination of Leishman-stained peripheral thin blood smear revealed $14.28 \%(12 / 84)$ positivity for the morulae of E. canis. E. canis was observed as intracytoplasmic inclusion bodies of varying sizes and shapes in monocytes. The majority of morulae were homogeneous and dense inclusions and more were detected in monocytes. The most commonly encountered form was the large spherical morulae of size $5.4 \mu \mathrm{m}$ (Figure-1).

\section{Seroprevalence}

Among 84 suspected dogs, 73 (86.90\%) dogs were seropostive to $E$. canis antibodies. High positive reaction to $E$. canis was seen in $53.57 \%(45 / 84)$ cases, medium positive reaction was in $22.61 \%$ (19/84) and

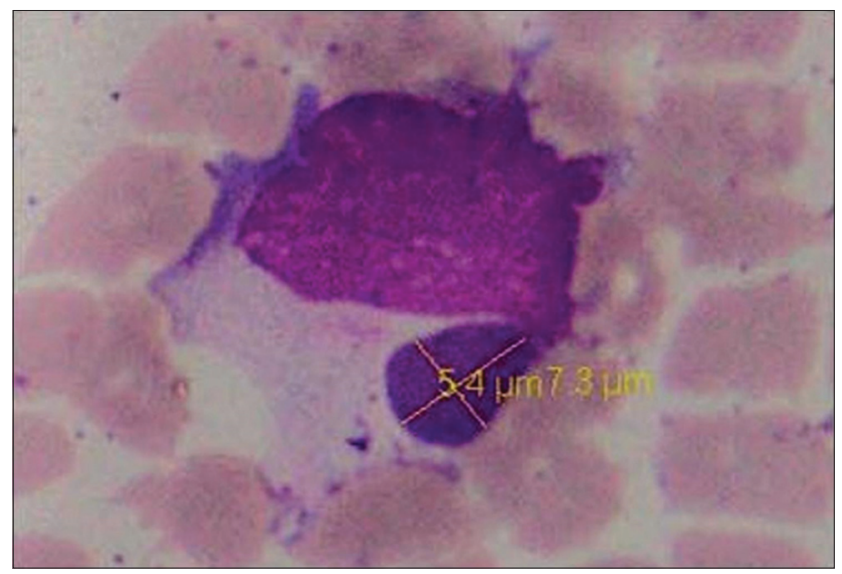

Figure-1: Ehrlichia canis morula of size $5.4 \mu \mathrm{m}$ in monocyte of dog. 
$10.71 \%(9 / 84)$ cases showed low positive reaction. Negative reaction was seen in $13.09 \%(11 / 84)$ cases. Reactions were characterized based on the intensity of the dot developed on the comb which was crossmatched with the combscale. The titer was graded according to the "S" levels on combscale on matching. It is a dot-ELISA detected by naked eye. Results were shown in Table-1 and interpreted according to standard data provided in the instructional manual with the ELISA-kit (Table-2). All blood smear positive cases (12) were also found to be seropositive.

\section{Age-wise and sex-wise prevalence}

Among the different age groups, 1-3 years of age group showed highest prevalence $(41.09 \%)$, followed by the 3-6 years age group (32.87\%), infection levels were lower in $<1$ year of age $(13.69 \%)$ and $>6$ year age group dogs $(12.32 \%)$. Higher prevalence was recorded in males $(71.23 \%)$ in comparison to females $(28.76 \%)$.

\section{Breed-wise distribution}

The highest prevalence was seen in Labrador retriever. A case was showing clear signs of ehrlichiosis positive by both microscopy and serology showed

Table-1: Screening of E. canis suspected cases by using IC ${ }^{\circledR}$ canine Ehrlichia antibody test kit (Biogal, Galed Labs.).

\begin{tabular}{|c|c|c|c|}
\hline Score & Titre & $\begin{array}{l}\text { Tooth } \\
\text { number and } \\
\text { results }(n=84)\end{array}$ & Percentage \\
\hline$\geq \mathrm{S} 5$ & $1: 320-1280$ & $\begin{array}{l}\text { Number of high } \\
\text { positive reaction to } \\
\text { E. canis } \\
45\end{array}$ & 53.57 \\
\hline S3-S4 & $1: 80-1: 160$ & $\begin{array}{l}\text { Number of medium } \\
\text { positive reaction to } \\
\text { E. canis } \\
19\end{array}$ & 22.61 \\
\hline $\mathrm{S} 1-2$ & $1: 20-1: 40$ & $\begin{array}{l}\text { Number of low } \\
\text { positive reaction to } \\
\text { E. canis } \\
9\end{array}$ & 10.71 \\
\hline so & $\mathrm{Nil}$ & $\begin{array}{l}\text { Negative reaction } \\
11\end{array}$ & 13.09 \\
\hline
\end{tabular}

high positive titer to $E$. canis antibodies (1:320-1280) (Figure-2). Usually, in study area and within the study period, Labrador retriever and German Shepherd dog (GSD) breeds were presented more to the clinics. So not much significance can be found on seasonal distribution of infected dogs in terms of breed wise. The detailed distribution and number of dog breeds seropositive to E. canis are shown in Table-3. Five cases of Labrador retriever, four cases of GSD were of aged between 2 and 5 years and two cases of Pomeranian 3 years of age found negative by serology.

\section{Season-wise distribution}

This study indicates that season plays a very important role in the prevalence of ehrlichiosis. This study shows a significant relation between the various seasons and the prevalence of the disease. Most of the cases seen in rainy season $(50.68 \%)$ followed by summer $(27.39 \%)$, autumn (12.32\%), and least in spring $(9.58 \%)$. No cases were reported in winter, which indicates a decrease in prevalence with a decrease in ambient temperature (Table-4).

\section{Clinical findings in serologically positive dogs}

Dogs positive by serology were having clinical signs such as fever $(38.35 \%)$, pale/congested mucus membrane $(32.87 \% / 34.24 \%)$, tick infestation $(60.27 \%)$, melena $(42.00 \%)$, anorexia $(42.46 \%)$, lymphadenopathy $(41.09 \%)$, loss of weight $(36.98 \%)$, inappetance $(38.35 \%)$, vomiting $(24.65 \%)$, respiratory distress $(15.06 \%)$, epistaxis $(24.65 \%)$, petechieal hemorrhages $(5.47 \%)$, depression $(4.10 \%)$, bleeding tendency $(6.84 \%)$, ocular discharge $(6.84 \%)$, edema of legs (1.36\%), and lethargy (8.21\%) (Table-5).

\section{Vital body parameters}

The mean \pm standard deviation values of rectal temperature $\left({ }^{\circ} \mathrm{F}\right)$ of seropositive dogs $\left(104.13 \pm 1.52^{\circ} \mathrm{F}\right)$ showed significant difference from the rectal temperature of control group $\left(92.01 \pm 0.71^{\circ} \mathrm{F}\right)$. Whereas no significant difference in heart rate and respiration rate were noted between the infected group and control group (Table-6).

\section{Hematobiochemical findings}

The most common findings observed were anemia, leukocytosis, neutropenia, lymphopenia,

Table-2: Interpretation of IgG antibody results and titers.

\begin{tabular}{|c|c|c|c|}
\hline Tooth No. & Results & & Remarks \\
\hline 1 & $\geq$ S5 & High positive reaction to $E$. canis & Titer $1: 320-1280$ \\
\hline 2 & S3-S4 & Medium positive reaction $E$. canis & Titer $1: 80-1: 160$ \\
\hline 3 & $\geq S 5$ & High positive reaction to $E$. canis & Titer $1: 320-128$ \\
\hline 4 & $\mathrm{~S} 1-2$ & Low positive reaction to $E$. canis & Titer $1: 20-1: 40$ \\
\hline 5 & so & Negative reaction to $E$. canis & Negative \\
\hline 6 & & No positive reference* & Invalid test \\
\hline 7 & & No positive reference* & Invalid test \\
\hline 8 & so & Negative reaction to $E$. canis & Negative \\
\hline 9 & & High background color - interferes with reading* & Invalid test \\
\hline 10 & $\geq \mathrm{S} 3$ & Positive reaction with high background & Positive \\
\hline 11 & S3-S4 & Medium positive reaction $E$. canis & Titer $1: 80-1: 160$ \\
\hline 12 & S1-2 & Low positive reaction to $E$. canis & Titer $1: 20-1: 40$ \\
\hline
\end{tabular}

IgG=Immunoglobulin-G, E. canis=Ehrlichia canis 


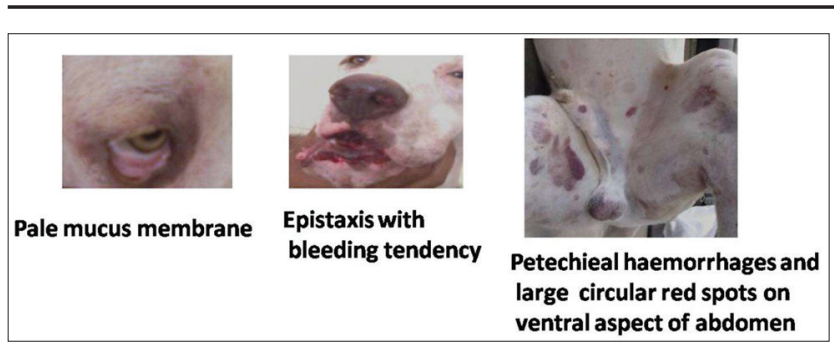

Figure-2: Indian bully breed of dog showing signs of ehrlichiosis.

Table-3: Breedwise seroprevalence of ehrlichiosis in dogs.

\begin{tabular}{lcc}
\hline Breed & $\begin{array}{c}\text { Seropositive } \\
\text { cases }(\mathbf{n = 7 3})\end{array}$ & Percent positive \\
\hline Labrador retriever & 33 & 45.20 \\
GSD & 11 & 15.07 \\
Pug & 5 & 6.84 \\
Saint Bernard & 5 & 6.84 \\
Rottweiler & 2 & 2.73 \\
Dalmatian & 1 & 1.36 \\
Great Dane & 1 & 1.36 \\
Pomeranian & 4 & 5.47 \\
Boxer & 2 & 2.73 \\
Indian Bully & 1 & 1.36 \\
Non descript & 1 & 1.36 \\
Pit Bull & 2 & 2.73 \\
Cocker Spaniel & 2 & 2.73 \\
Spitz & 1 & 1.36 \\
Beagle & 1 & 1.36 \\
Bull terrier & 1 & 1.36 \\
\hline
\end{tabular}

GSD $=$ German shepherd dog thrombocytopenia, eosinophilia followed by hyperbilirubinemia, increased level of AST, ALT and ALKP, hypoalbuminemia, hyperglobulinaemia, decrease in albumin and globulin ratio, increase in BUN and creatinine. A significant decrease in the mean values of $\mathrm{Hb}$, packed cell volume (PCV), platelets, albumin and globulin ratio and increase in the mean values of AST, ALT, ALKP globulin and creatinine were found (Tables-7 and 8).

\section{Discussion}

\section{Blood smear examination and clinical findings}

Our microscopic study was agreeing with the findings of Eljadar [6] who reported 7.9\% (75/951) of the cases were positive for ehrlichiosis by blood smear examination. Milanjeet [7] found $2.34 \%$ of cases to be positive for E. canis morulae in the same region of Punjab. Dhankar et al. [8] found $11.35 \%$ dogs positive for ehrlichiosis in Haryana and Delhi states. Our clinical findings in dogs with canine monocytic ehrlichiosis are agreeing with the findings of Das and Konar [9] and Sacchini et al. [10]. Shipov et al. [11] mentioned in their study about $37.5 \%$ of positive cases were having rectal temperature more than $107.25^{\circ} \mathrm{F}$.

\section{Age- and sex-wise distribution}

In this study, we have seen that 1-3 years of age group dogs showed the highest prevalence.

Table-4: Season wise seroprevalence of ehrlichiosis in dogs.

\begin{tabular}{lccccc}
\hline Seasons & $\begin{array}{l}\text { Total number } \\
\text { of cases (84) }\end{array}$ & Seropositive cases (73) & Seronegative cases (11) & Percent positive & Percent negative \\
\hline Summer & 22 & 20 & 2 & 27.39 & 18.18 \\
Rainy & 40 & 37 & 3 & 50.68 & 27.27 \\
Autumn & 12 & 9 & 3 & 12.32 & 27.27 \\
Winter & 0 & 0 & 0 & 0 & 0 \\
Spring & 10 & 7 & 3 & 9.58 & 27.27 \\
\hline
\end{tabular}

Table-5: Clinical findings in serologically positive dogs.

\begin{tabular}{|c|c|c|c|c|}
\hline \multirow[t]{2}{*}{ Clinical signs/findings } & \multicolumn{2}{|c|}{ Total number of samples examined (84) } & \multirow{2}{*}{$\begin{array}{l}\text { Percent } \\
\text { positive }\end{array}$} & \multirow{2}{*}{$\begin{array}{l}\text { Percent } \\
\text { negative }\end{array}$} \\
\hline & Positive by serology (73) & Negative by serology (11) & & \\
\hline$\overline{P M M}$ & 24 & 2 & 32.87 & 18.18 \\
\hline CMM & 25 & 5 & 34.24 & 45.45 \\
\hline Inappetance & 28 & 4 & 38.35 & 36.36 \\
\hline Anorexia & 31 & 2 & 42.46 & 18.18 \\
\hline Tick infestation & 44 & 8 & 60.27 & 72.72 \\
\hline Fever & 28 & 7 & 38.35 & 63.63 \\
\hline Weakness & 35 & 5 & 47.94 & 45.45 \\
\hline Depression & 3 & 0 & 4.10 & 0 \\
\hline Lethargy & 6 & 0 & 8.21 & 0 \\
\hline Vomiting & 18 & 0 & 24.65 & 0 \\
\hline Melena & 31 & 3 & 42.46 & 27.27 \\
\hline Respiratory distress & 11 & 3 & 15.06 & 27.27 \\
\hline Lymphadenopathy & 30 & 4 & 41.09 & 36.36 \\
\hline Loss of weight & 27 & 4 & 36.98 & 36.36 \\
\hline epistaxis & 18 & 3 & 24.65 & 27.27 \\
\hline Bleeding tendency & 5 & 0 & 6.84 & 0 \\
\hline Occular discharge & 5 & 0 & 6.84 & 0 \\
\hline Corneal opacity & 4 & 0 & 5.47 & 0 \\
\hline Hindlimb weakness & 11 & 2 & 15.06 & 18.18 \\
\hline Oedema of legs & 1 & 0 & 1.36 & 0 \\
\hline Seizures & 4 & 0 & 5.47 & 0 \\
\hline Petechieal hemorrhages & 4 & 0 & 5.47 & 0 \\
\hline
\end{tabular}

$\mathrm{CMM}=$ Congested mucus membrane, $\mathrm{PMM}=$ Pale mucus membrane 
Table-6: Study of vital body parameters in dogs positive for ehrlichiosis.

\begin{tabular}{lcccc}
\hline Parameters (0 day) & $\begin{array}{c}\text { Rectal } \\
\text { temperature ( }{ }^{\circ} \text { F) }\end{array}$ & Heart rate (per minute) & $\begin{array}{c}\text { Respiration } \\
\text { rate (per minute) }\end{array}$ & $\begin{array}{c}\text { Pulse rate (per } \\
\text { minute) }\end{array}$ \\
\hline Sero positive cases $(n=73)$ & $104.13 \pm 1.52^{\mathrm{b}}$ & $89.17 \pm 11.01^{\mathrm{a}}$ & $29.36 \pm 7.13^{\mathrm{a}}$ & $87.58 \pm 10.97^{\mathrm{a}}$ \\
Control $(\mathrm{n}=10)$ & $92.01 \pm 0.71^{\mathrm{a}}$ & $90.3 \pm 11.69^{\mathrm{a}}$ & $29.8 \pm 2.15^{\mathrm{a}}$ & $88.8 \pm 11.50^{\mathrm{a}}$ \\
\hline
\end{tabular}

$\mathrm{a}, \mathrm{b}: 5 \%$ level of significance

Harrus et al. [12] observed disease in all age groups. Harikrishnan et al. [13] reported dogs aged from 15 days to 15 years were affected with ehrlichiosis indicating that all the ages of dogs are susceptible to ehrlichiosis. Abiramy et al. [14] observed that maximum cases of canine ehrlichiosis (36\%) were observed in dogs of 5-10 years of age and maximum cases were noticed in female dogs. Costa et al. [15] observed male dogs more than 5 years of age had higher rates of anti-E. canis antibodies.

\section{Breed- and season-wise distribution}

In this study, the disease prevalence was highest in Labrador retriever breed of dogs as compared to others (Table-1). Chandrasekar et al. [16] and Bhadesiya and Modi [17] also found that Labrador breed of dogs was also most susceptible. In our study, the disease was found to be most prevalent in rainy and summer followed by autumn and least in spring season. The probable reason behind this trend may be correlated to the seasonal activity of the brown dog tick, $R$. sanguineus was more abundant in hot and humid period of the year by Soulsby [18]. Similarly, Eljadar [6] from Ludhiana, Punjab recorded maximum prevalence of the disease during the summer season with the prevalence rate of $56 \%$ followed by rainy season (37\%).

\section{Serological examination}

Mainly our results are agreeing with the similar work previously done by Eljadar [6] in the same region of Punjab, found that $93.33 \%(70 / 75)$ cases were positive by serology. Harikrishnan et al. [13] detected E. canis antibodies in sera from 21 out of 56 dogs $(37.5 \%)$ in ELISA and 23 dogs $(41.1 \%)$ in dot-ELISA. They stated that ELISA is a valuable tool for diagnosing the subclinical and chronic forms of canine ehrlichiosis. Akhtardanesh et al. [19] found overall seroprevalence of ehrlichiosis was $14.63 \%$ which was determined as $13.8 \%$ and $10.6 \%$ using IFA test and rapid immunochromatography, respectively.

de Castro et al. [20] in their work stated that after 30 days of inoculation all the infected dogs showed positive titers for $E$. canis by testing all the samples for specific IgG response to E. canis with dot-blot ELISA kit (IC ${ }^{\circledR}$, Biogal). Sasanelli et al. [21] reported a case with an antibody titer of 1:160. Castro [22] and Oria [23] used the IC test to determine IgG antibodies specific for the organism. Variable prevalence of ehrlichiosis has been reported from various parts of India. Kumar et al. [24] reported overall positivity for E. canis 6\% (29/485) in canines from Chennai city. Chipde et al. [25] had shown $42.85 \%$ prevalence of canine ehrlichiosis in Nagpur city. Ybanez et al. [26] found 438/913 cases were serologically positive for E. canis using $\mathrm{IC}^{\circledR}$ (Biogal) test kit and positive dogs produced varied clinical signs that may be influenced by the thrombocytopenic and anemic states of affected animals.

\section{Hematobiochemical findings of ehrlichiosis}

Thrombocytopenia, anemia, hypoalbuminemia, increase in ALKP, decreased albumin and globulin ratio were the most common findings in diagnosing canine ehrlichiosis. This study depicts $100 \%$ prevalence of thrombocytopenia in E. canis seropositive dogs. A similar study by Bhadesiya and Modi [17] evidenced that the mean values of $\mathrm{Hb}, \mathrm{PCV}$, TEC, TLC, and total platelet count were significantly deceased in dogs which are positive by $\mathrm{IC}^{\circledR}$ test kit. Sasanelli et al. [21] showed increased levels of ALT, AST, ALKP, BUN, creatinine and total bilirubin. Asgarali et al. [27] stated that thrombocytopenia is a common finding in dogs with ehrlichiosis. Akhtardanesh et al. [19] found $16.66 \%$ seropositive cases displayed hyperglobulinemia, thrombocytopenia, leukopenia, anemia, and high ALKP level. Kuehn and Gaunt [28] reported low albumin globulin ratio as serum biochemical abnormality in natural infection with E. canis. Mylonakis et al. [29] observed hypoalbuminemia and increased level of ALT activity in dogs with ehrlichiosis.

In summary, it can be concluded that $\mathrm{IC}^{\circledR}$ canine Ehrlichia antibody test kit can be used for both prevalence study as well as pen side diagnostic tool in diagnosing CME, apart from the routinely used conventional methods and above-mentioned hematobiochemical alterations must be included in the differential diagnosis when these are observed during routine laboratory evaluations.

\section{Conclusions}

Since in India, prevalence and distribution of ehrlichiosis remain largely unexplored, serological techniques like $\mathrm{IC}^{\circledR}$ are more useful for detecting chronic and subclinical infections and are ideally suited to epidemiological investigations. IC ${ }^{\circledR}$ canine Ehrlichia antibody test kit can be used as a pen-side test kit in diagnosing canine monocytic ehrlichiosis.

\section{Authors' Contributions}

MRK: Conducted research work and prepared manuscript: PSD: Designed research work and Procured IC $^{\circledR}$ antibody test kit,; LDS: Conducted microscopic examination of the blood smear, helped in preparation of manuscript; BKB: Provided research 


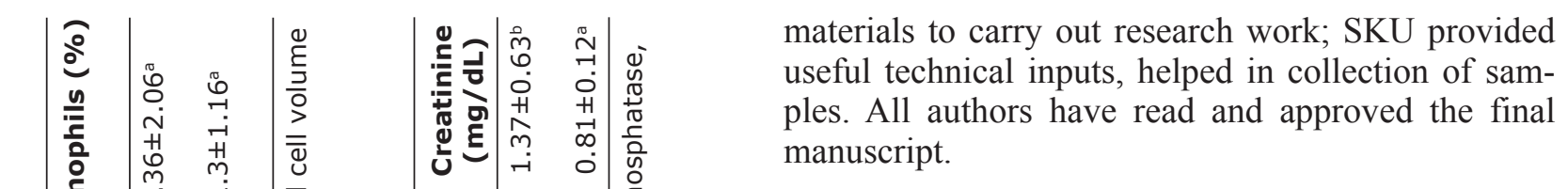

\section{Acknowledgments}

We are very grateful to the Director of Research, Guru Angad Dev Veterinary and Animal Sciences University, Ludhiana, Punjab, for providing the necessary facilities. Financial support in purchase of test kits by Deaptment of veterinary medicine, GADVASU, Ludhiana.

\section{Competing Interests} interests.

The authors declare that they have no competing

\section{References}

1. Shukla, S., Parihar, S., Bariya, S. and Chaturvedi, A. (2011) A clinic-pathological report of canine ehrlichiosis in a Doberman pinscher. Vet. World, 4(8): 374-375.

2. Singla, L.D., Singh, H., Kaur, P., Singh, N.D., Singh, N.K. and Juyal, P.D. (2011) Serodetection of Ehrlichia canis infection in dogs from Ludhiana district of Punjab, India. J. Parasit. Dis., 35: 195-198.

3. Waner, T., Strenger, C. and Keysary, A. (2000) Comparison of a clinic-based ELISA test kit with the immunofluorescence test for the assay of Ehrlichia canis antibodies in dogs. J. Vet. Diagn. Invest., 12: 240-244.

4. Oliveira, D., Tie-Nishmori, C., Costa, M.T., Machado, R.Z. and Castro, M.B. (2000) Anti-Ehrlichia canis antibodies detection by "dot-ELISA" in naturally infected dogs. Rev. Bras. Parasitol. Vet., 9(1): 1-5.

5. Baticados, A.M. and Baticados, W.N. (2011) Serological evidence for Ehrlichia canis exposure in military dogs and other canines in Metropolitan Manila, Philippines. Isr. J. Vet. Med., 66(4): 151-156.

6. Eljadar, M.S.M. (2010) 'Clinico - Diagnostic Studies on Vector Transmitted Haemoprotozoan Diseases in Dog.' M.V.Sc. Thesis. Guru Angad Dev Veterinary and Animal Sciences University, Ludhiana, Punjab.

7. Milanjeet, H.S. (2013) Prevalence and molecular tetection of canine monocytic ehrlichiosis. M.V.Sc. Thesis, Guru Angad Dev Veterinary and Animal Sciences University, Ludhiana, Punjab.

8. Dhankar, S., Sharma, R.D. and Jindal, N. (2011) Epidemiological observations on canine ehrlichiosis in Haryana and Delhi states. Haryana Vet., 50: 9-14.

9. Das, M. and Konar, S. (2013) Clinical and haematological study of canine ehrlichiosis with other hemoprotozoan parasites in Kolkata, West Bengal, India. Asian Pac. J. Trop. Biomed., 3(11): 913-915.

10. Sacchini, F., Cessford, R.J. and Robinson, B.M. (2007) Outbreak of canine monocytic ehrlichiosis in Saudi Arabia. Vet. Clin. Pathol., 36(4): 331-35.

11. Shipov, A., Klement, E., Tager, L.R., Waner, T. and Harrus. S. (2008) Prognostic indicators for canine monocytic ehrlichiosis. Vet. Parasitol., 153: 131-138.

12. Harrus, S., Kass, P.H., Klement, E. and Waner, T. (1997) Canine monocytic ehrlichiosis: A retrospective study of 100 cases and an epidemiological investigation of prognostic indicators for the disease. Vet. Rec., 141: 360-363.

13. Harikrishnan, T.J., Chellapa, D.J., Pazhanival, N., Sreekumar, C., Anna, T., Raman, N. and Rajavelu, G. (2001) Epizootiology of canine ehrlichiosis. Vet. Parasitol., 66: 241-249.

14. Abiramy, A., Rao, V.N., Vijayalakshmi, R., Das, S.S. and Kumar, R. (2007) Occurrence of canine ehrlichiosis in 
Pondicherry area and its treatment. Indian J. Vet. Med., 27(1): 81-82.

15. Costa, L.M. Jr., Rembeck, K., Ribeiro, M.F.B., Beelitz, P., Pfister, K. and Passos, L.M.F. (2007) Sero-prevalence and risk indicators for canine ehrlichiosis in three rural areas of Brazil. Vet. J., 174(3): 673-676.

16. Chandrasekar, M., Nambi, A.P., Ramprabhu, R. and Dhanapalan, P. (2002) Epizootiological studies on canine ehrlichiosis. Indian vet. J., 79(12): 85-86.

17. Bhadesiya, C.M. and Modi, D.V. (2015) Correlation of epidemiology of Rhipicephalous sanguineus and canine ehrlichiosis in nine different localities of middle Gujarat. Int. Agric.Sc. \& Vet.Med, 3(1): 2320-3730.

18. Soulsby, E.J.L. (1982) Helminths, Arthropods and Protozoa of Domesticated Animals. $7^{\text {th }}$ ed. Bailliere Tindall, London. p464.

19. Akhtardanesh, B., Ghanbarpour, R. and Blourizadeh, H. (2010) Serological evindence of canine monocytic ehrlichiosis in Iran. Comp. Clin. Path., 19: 469-474.

20. de Castro, M.B., Machado, R.Z., de Aquino, L.P.C., Alessi, A.C. and Costa, M.T. (2004) Experimental acute canine monocytic ehrlichiosis: Clinicopathological and immunopathological findings. Vet. Parasitol., 119: 73-86.

21. Sasanelli, M., Paradies, P., Lubas, G., Otranto, D. and de Caprariis, D. (2009) Atypical clinical presentation of coinfection with Ehrlichia, Babesia and Hepatozoon species in a dog. Vet. Rec., 164: 22-23.

22. Castro, M.B., Machado, R.Z., Alessi, A.C. and Aquino, L.P.C. (1997) Ehrlichia canis (Donatien and Lestoquard, 1935): Experimental infection in dogs. In:
Proceedings of the $\mathrm{IV}^{\text {th }}$ Biennial Meeting Society for Tropical Veterinary Medicine, Montpellier, French.

23. Oriá, A.P. (2001) Correlation between uveitis, clinical pathology, serological findings (indirect immunofluorescence reaction and Dot-blot ELISA) and pathology of the eye bulb in canine species, naturally and experimentally infected with Ehrlichia canis.p69.

24. Kumar, S.K., Vairamuthu, S. and Kathiresan, D. (2009) Prevalence of haemoprotozoans in canines in Chennai city. Tamilnadu J. Vet. Anim. Sci., 5: 104-108.

25. Chipde, V.S., Rode, A.M., Pradhan, M.S., Dakshinkar, N.P. and Sarode, D.B. (2007) Prevalence of canine ehrlichiosis in Nagpur city. R. Vet. J. India, 3(2): 121-123.

26. Ybañez, A.P., Ybañez, R.H.D., Villavelez, R.R., Malingin, H.P.F., Barrameda, D.N.M., Naquila, S.V. and Olimpos, S.M.B. (2016) Retrospective analyses of dogs found serologically positive for Ehrlichia canis in Cebu, Philippines from 2003 to 2014. Vet. World, 9(1): 43-47.

27. Asgarali, Z., Pargass, I., Adam, J., Mutani, A. and Ezeokoli, C. (2012) Haematological parameters in stray dogs seropositive and seronegative to Ehrlichia canis in north Trinidad. Ticks and tick borne diseases 3: 207-211.

28. Kuehn, N.F. and Gaunt, S.D. (1985) Clinical and haematologic findings in canine ehrlichiosis. J. Am. Vet. Med. Assoc., 186: 355-358

29. Mylonakis, M.E., Koutinas, A.F., Breitschwerdt, E.B., Hegarty, B.C., Billinis, C.D., Leontides, L.S. and Kontos, V.S. (2004) Chronic canine ehrlichiosis (Ehrlichia canis): A retrospective study of 19 natural cases. J. Am. Vet. Med. Assoc., 40(3): 174-184. 